\title{
INFLUENCE OF CONSERVATION METHOD (FREEZING AND DRYING) ON COMPOSITION AND CONTENT OF BIOLOGICALLY ACTIVE SUBSTANCES IN ROSACEAE FRUITS (CRUDE HERBAL DRUGS)
}

\author{
EKATERINA VYACHESLAVOVNA SERGUNOVA*, DMITRY OLEGOVICH BOKOV ${ }^{1,2,3}$
}

\begin{abstract}
${ }^{1}$ Department of Pharmaceutical and Natural Sciences, Sechenov First Moscow State Medical University, 8 Trubetskaya St., Bldg. 2, 119991, Russia. ${ }^{2}$ Department of Analytical, Physical and Colloid Chemistry, Sechenov First Moscow State Medical University, 8 Trubetskaya St., Bldg. 2, 119991, Russia. ${ }^{3}$ Laboratory of Food Chemistry, Federal Research Center for Nutrition, Biotechnology and Food Safety, 2/14, Ustyinsky Pr., Moscow, 109240, Russia. Email: nakasl@mail.ru
\end{abstract}

Received: 10 December 2018, Revised and Accepted: 21 December 2018

\begin{abstract}
Objective: Now, five crude herbal drugs (CHD) of fruit morphological group (fruits) related to Rosaceae family included in the Russian State Pharmacopoeia XI and XIII editions: Fructus Rosae (Rosa cinnamomea L. and other species), Fructus Crataegi (Crataegus sanguinea Pall. and other species), Fructus Sorbi (Sorbus aucuparia L.), Fructus Rubi (Rubus idaeus L.), and Fructus Aroniae (Aronia melanocarpa [Michx.] Elliott).The aim of this study was to investigate the effect of freezing and oven drying on the composition and content of individual groups of biologically active substances (BAS) in Rosaceae fruits.
\end{abstract}

Methods: The groups of BAS were investigated by UV spectrophotometry (flavonoids and anthocyanins), galvanostatic coulometry titration (organic acids), gravimetry (polysaccharides), and titration with potassium permanganate (tannins).

Results: The relation between content of BAS (total free organic acids, total flavonoids, total anthocyanins, total tannins, and total polysaccharides) and fruits conservation method was determined. In frozen fruits total polysaccharides, total free organic acids and ascorbic acid content decreased by $5-7 \%$, total flavonoids and total tannins content decreased by $10-15 \%$, total anthocyanins content decreased by $25-30 \%$. Fruits oven drying at $60-80^{\circ} \mathrm{C}$ leads to more significant losses of total anthocyanins, ascorbic acid, and total free organic acids.

Conclusion: The study of BAS stability in frozen and dried fruits was lasting for 12 months. The duration of shelf life for frozen fruits is recommended. Freezing as a conservation method allows to preserve more BAS in Rosaceae fruits. Frozen CHD can be proposed as an alternative to fresh and dried $\mathrm{CPB}$ for the preparation of allopathic and homeopathic medicines.

Keywords: Rosaceae fruits, Rosa cinnamomea, Crataegus sanguinea, Sorbus aucuparia, Rubus idaeus, Aronia melanocarpa, Crude herbal drugs, Drying, Freezing, Total free organic acids, Total flavonoids, Total anthocyanins, Total tannins, Total polysaccharides.

(c) 2019 The Authors. Published by Innovare Academic Sciences Pvt Ltd. This is an open access article under the CC BY license (http://creativecommons. org/licenses/by/4. 0/) DOI: http://dx.doi.org/10.22159/ajpcr.2019.v12i1.29662

\section{INTRODUCTION}

Rosaceae fruits (Fructus) are widely used in Russian medical practice crude herbal drugs (CHDs). Rosaceae fruits are delivered to the pharmacy in a packaged form for OTC distribution and used for the preparation of water extracts. Rosaceae fruits are part of medicinal teas composition, serve as raw materials for obtaining of tinctures and extracts, and are used in homeopathy [1,2]. Fresh fruits have the richest biologically active substances (BAS) composition [3,4]. Flavonoids (flavonols and anthocyanins), simple sugars, polysaccharides, tannins, and organic and hydroxycinnamic acids are among them [5-9]. Different complex drugs with wide range of pharmacological activity are produced from them $[10,11]$.

Fresh fruits contain BAS complex presented in the plant in natural state. However, due to the high moisture content, fresh juicy fruits are exposed to enzymatic breakup and microbial contamination, these factors limit its use $[12,13]$.

Conventionally, CHDs are subjected to drying $[14,15]$. An alternative method of conservation is freezing [16,17]. Due to the absence of a liquid phase, the activity of enzymes ceases, and as a result, biochemical processes are suspended. Both drying and freezing have their advantages and disadvantages, because during these processes, the content of BAS in the raw materials varies, which can lead to a decrease in the quality of CHD.
The drying method, temperature and velocity of drying air influence the quantity and quality of BAS presented in CHD. Research data indicate that drying air temperatures between 50 and $60^{\circ} \mathrm{C}$ appear to be suitable for drying different CHD types [18]. In Aronia melanocarpa fruits, the highest content of total flavonoids, polyphenols, and total anthocyanins was detected in freeze-dried CHD, then sun and oven drying CHDs follow in descending order [19].

Freeze-drying (lyophilization) is another modern procedure that very effective preserves BAS in CHD, and much better than other preservation methods but requires special equipment. Review study shows that freeze-drying is imperfect method to preserve important BAS classes (such as carotenoids, volatiles, and phenolics) and should be used carefully [20].

It is important to study the variability of the chemical composition of BAS in fruits depending on the conservation method, to identify the most effective way of preserving the quality of CHD. Another important aspect is providing new types of CHD by introduction of new sources of raw materials (fresh, frozen CHD), along with the traditional dried ones.

\section{METHODS}

Plant materials

The subjects of the study were test samples of fresh, frozen, and dried fruits of Siberian hawthorn (Crataegus sanguinea Pall.), 
mountain-ash (Sorbus aucuparia L.), black chokeberry (A. melanocarpa [Michx.] Elliott), European raspberry (Rubus idaeus L.), and cinnamon rose (Rosa cinnamomea L.), collected in the Botanical Garden of Sechenov First Moscow State Medical University and in the Moscow region. Plants and fruits have been identified by the head of Pharmaceutical Natural Sciences Department, Luferov Alexander Nikolaevich and professor of Pharmaceutical Natural Sciences Department, Sergunova Ekaterina Vyacheslavovna; voucher specimens were deposited at the Pharmaceutical Natural Sciences Department Herbarium. CHD test samples were dried in an oven (laboratory drying cabinet) at a temperature of $60-80^{\circ} \mathrm{C}$ and stored at room temperature $\left(20-25^{\circ} \mathrm{C}\right)$. CHD test samples were frozen according to GOST R 53956-2010 "Quickfrozen fruits. General specifications." Fruits were stored in a freezing chamber at a temperature of $-18^{\circ} \mathrm{C}$.

\section{Chemicals}

Commercially available individual substances were used as reference standards. Organic acids reference standards - L-ascorbic acid (CAS No. 50-81-7, 99, 5\%), citric acid monohydrate (CAS No. 5949-29-1, 99, 5\%), and D,L-malic acid (CAS No. 6915-15-7, 99, 0\%) - were received from Fuso Chemical Co., Ltd. (Japan) and rutoside (rutin trihydrate CAS No. 250249-75-3, 94,0\%) was received from Sigma-Aldrich (USA).

\section{Determination of BAS content}

Galvanostatic coulometry method was applied to quantify the content of ascorbic acid and total free organic acids using coulometer Expert-006 (Ekoniks-Expert, Russia) with $5 \mathrm{~mA}$ current. The content of total free organic acids was determined by titration with electrically generated hydroxide ions with $\mathrm{pH}$-metric fixation of the end point of titration. Ascorbic acid content was determined by titration with electrically generated iodine. The titration end point was determined by amperometrically [21].

Total flavonoids and total anthocyanins content in the fruits was determined by spectrophotometry method $[22,23]$ using Cary Varian 4000 spectrophotometer (Agilent Technologies, USA). Rutoside was chosen as the reference standard to determine total flavonoids content in hawthorn, cinnamon rose, and mountain-ash fruits. The complexes of the fruits flavonoids and rutoside with aluminum chloride have the same absorption maximum at a wavelength of $410 \mathrm{~nm}$, the procedure described in pharmacopoeial monograph “St. John's Wort herb - Herba hyperici" [2] (Fig. 1). The total anthocyanins content was determined in terms of cyanidin-3,5-diglucoside. Cyanidin-3,5-diglucoside spectrum has identical characteristics with water-alcohol raspberry fruit extract (absorption maximum at 510-520 $\mathrm{nm}$ ), the procedure described in monograph "Cornflower flowers - Flores Centaureae cyani" [2]. Cyanidin-3-0-glucoside (absorption maximum at $534 \mathrm{~nm}$ ) is relevant reference standard for black chokeberry fruits according to monograph "Bilberry fruit, fresh - Myrtilli fructus recens" (Fig. 2) [24].

The content of total polysaccharides was determined by gravimetry method according "Broadleaf plantain leaves - Folia Plantaginis majoris" [2]. Content of total tannins in terms of tannin was determined by titration with potassium permanganate according to general pharmacopoeial monograph "Determination of the content of tannins in medicinal plant raw materials" [25].

\section{Ascorbic acid assay}

An analytical sample weighing $5.0 \mathrm{~g}$ (exact weight sample) of dried fruit (crushed) and fresh-frozen fruit (homogenized suspension) was placed in a porcelain mortar where it was carefully grounded with glass powder (about $5 \mathrm{~g}$ ), $150 \mathrm{ml}$ of the purified water was added and remained for infusion for $10 \mathrm{~min}$. The resulting extract was mixed and filtered through a paper fold filter.

About $0.5 \mathrm{ml}$ of the extract from the fruit and the standard solution was placed into a coulometric cell filled with electrolyte - 0.1 M KI solution in hydrochloric buffer solution $(\mathrm{pH}=1.2)$, and a measurement was performed using coulometric titrator. Titration was performed by electrically generated iodine.
Total free organic acids assay

Approximately 5.0 g (exact weight sample) of dried fruit (crushed) and fresh-frozen fruits (homogenized suspension) was placed into $200 \mathrm{ml}$ glass-stoppered flask, $150 \mathrm{ml}$ of the purified water was added and held for $2 \mathrm{~h}$ in a boiling water bath. The resulting extract was cooled and filtered through a paper fold filter into a $200 \mathrm{ml}$ volumetric flask. The volume of the extract was adjusted to the mark with the purified water and mixed.

About $0.5 \mathrm{ml}$ of the extract was placed into the coulometric cell filled with a background electrolyte, an aqueous solution of potassium sulfate. The measurement was performed using coulometric titrator. The titration was carried out with hydroxide ions generated by the device.

\section{Total anthocyanins assay in raspberry fruits}

Approximately $5.0 \mathrm{~g}$ (exact weight sample) of fresh, frozen, and dried (crushed) fruits was placed into a $250 \mathrm{ml}$ glass-stoppered flask, $100 \mathrm{ml}$ of a $1 \%$ hydrochloric acid solution was added, and the flask was kept in a water bath at a temperature of $40-45^{\circ} \mathrm{C}$ for $15 \mathrm{~min}$. The extract was filtered through cotton wool into $250 \mathrm{ml}$ volumetric flask. The cotton wool with raw material was placed into a flask again, $100 \mathrm{ml}$ of a $1 \%$ solution of hydrochloric acid was added, preliminarily washing the particles of the raw material from the funnel into a flask, and the extraction process was repeated by the above method. Then, the contents of the flask were filtered through cotton wool into the same volumetric flask. The filter cake was washed with $40 \mathrm{ml}$ of a $1 \%$ hydrochloric acid solution. After the filtrate was cooled, the volume of extract was adjusted to the mark with a $1 \%$ solution of hydrochloric acid. The resulting extract was filtered through a paper filter into a $250 \mathrm{ml}$ flask, discarding the first $10 \mathrm{ml}$ of the filtrate and measuring the optical density of the filtrate on a spectrophotometer at a wavelength of $510 \mathrm{~nm}$ in a cell with layer thickness of $10 \mathrm{~mm}$. 1\% solution of hydrochloric acid was used as the reference solution. The content was calculated using the specific absorption index of cyanidin-3,5diglucoside (453).

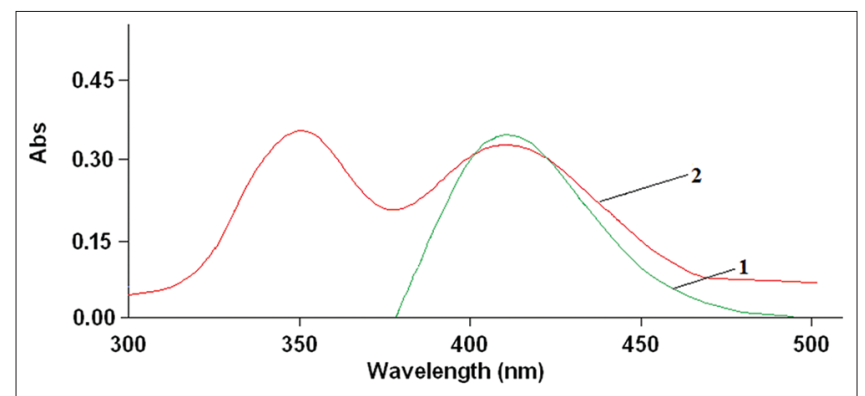

Fig. 1: Absorption spectra of rutoside complexes (1) and flavonoids from cinnamon rose fruits (2) with aluminum chloride

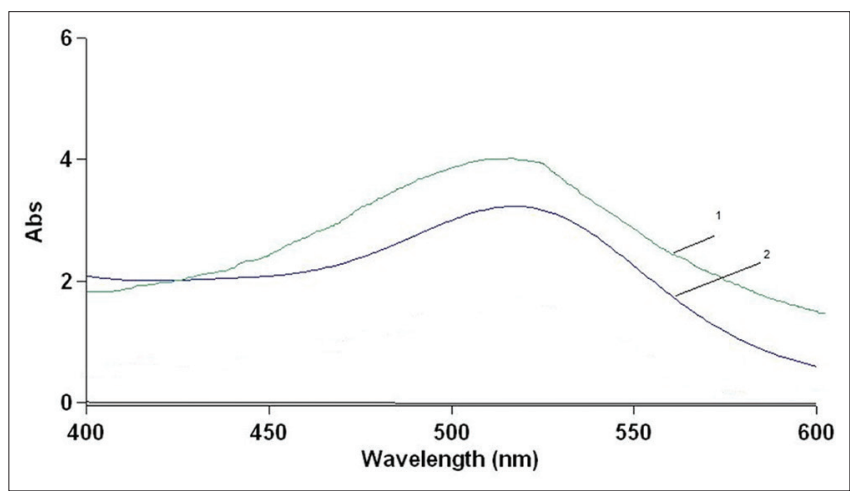

Fig. 2: The absorption spectra of cyanidin-3-0-glucoside (1) and anthocyanins from fruits of black chokeberry (2) 


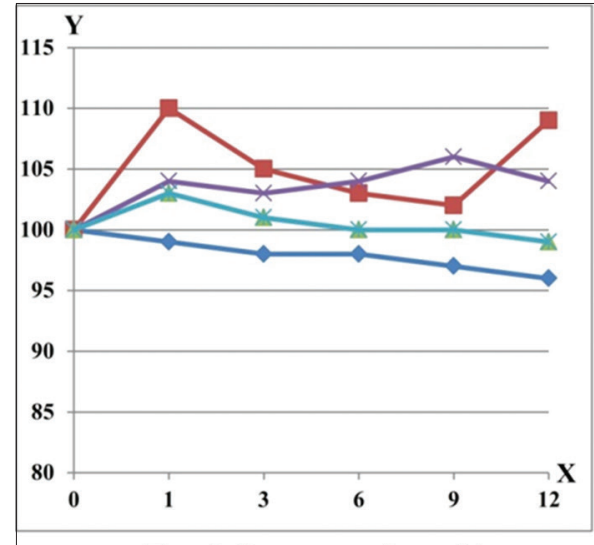

Total free organic acids

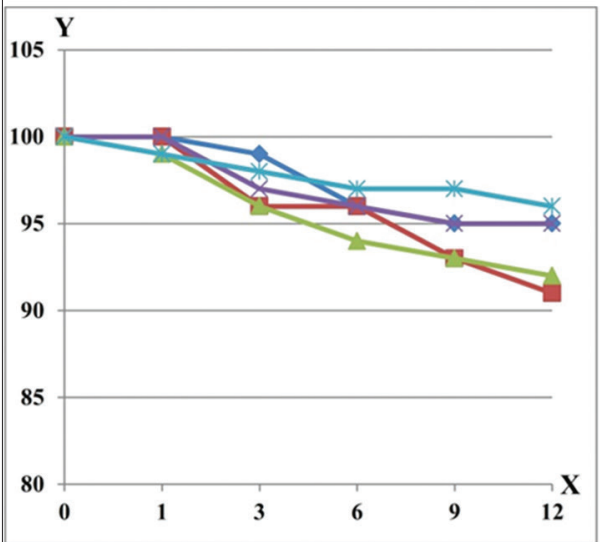

Total flavonoids

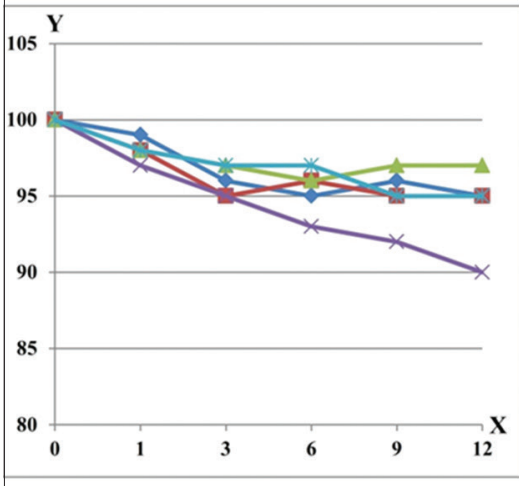

Total polysaccharides

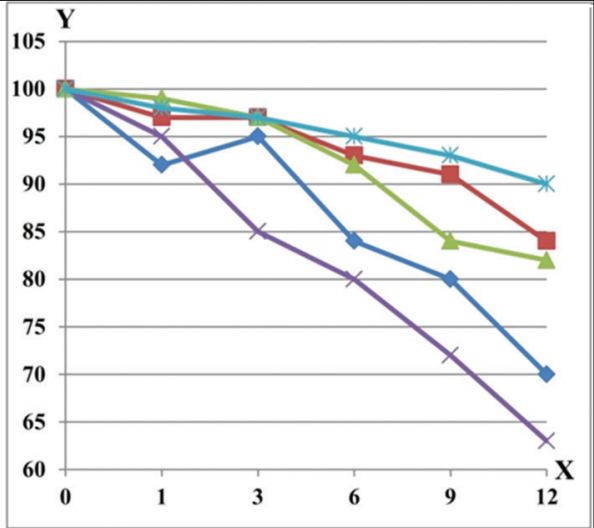

Ascorbic acid

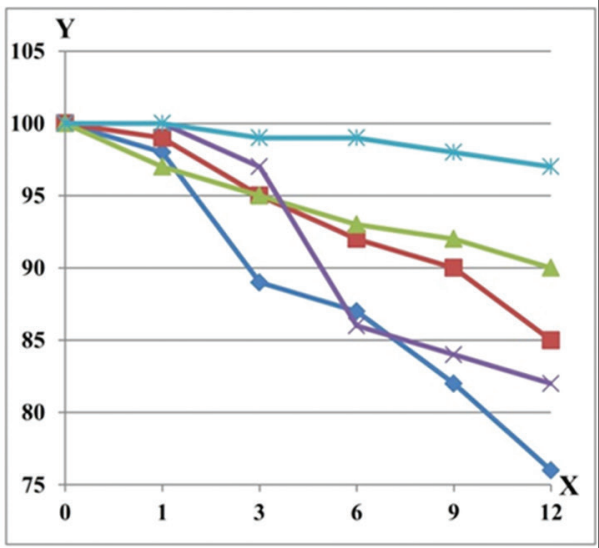

Total tannins

$-\quad$ Hawthorn fruits
$-\quad$ Mountain-ash fruits
$* \quad$ Raspberry fruits
$* \quad$ Cinnamon rose fruits
$\quad$ Black chokeberry fruits
Y-axis - part of BAS from the initial content, \%
$\mathrm{X}$-axis - time, months

Fig. 3: Dynamics of biologically active substances content during the storage of frozen Rosaceae fruits. The results of total anthocyanins determination are presented for raspberry and black chokeberry fruits as total flavonoid content

Total anthocyanins assay in black chokeberry fruits

Approximately $5.0 \mathrm{~g}$ (exact weight sample) of fresh, frozen, and dried (crushed) fruits was placed into a $100 \mathrm{ml}$ glass-stoppered flask, $50 \mathrm{ml}$ of $60 \%$ ethanol containing $1 \%$ of hydrochloric acid was added. The flask was closed with a grounded glass stopper. The flask was attached to a reflux condenser and heated in a boiling water bath for $90 \mathrm{~min}$. The extract was filtered through a paper filter. $1 \mathrm{ml}$ of the obtained extract was placed in a $25 \mathrm{ml}$ volumetric flask and adjusted to the mark with $1 \%$ solution of hydrochloric acid in $95 \%$ ethanol. The optical density was measured in a cell with a layer thickness of $1 \mathrm{~cm}$ at a wavelength of $534 \mathrm{~nm} .95 \%$ ethanol was used as the reference solution. The total anthocyanins content was calculated using the specific absorption index of cyanidin-3-0-glucoside (100).

\section{RESULTS AND DISCUSSION}

Research data presented in Table 1 show that the fruits freezing results in a slight (by 5-7\%) decrease in the amount of total polysaccharides and ascorbic acid. The content of total flavonoids and total tannins in frozen fruits decreased on average by $10-20 \%$, total free organic acids content was preserved up to $90 \%$ of their initial value in fresh CHD, and the content of total anthocyanins has dropped by $30 \%$.

The results of total anthocyanins determination are presented for raspberry and black chokeberry fruits as total flavonoid content.

Under the influence of high temperatures, the content of total free organic acids decreased by $45-60 \%$; total tannins, ascorbic acid, and 


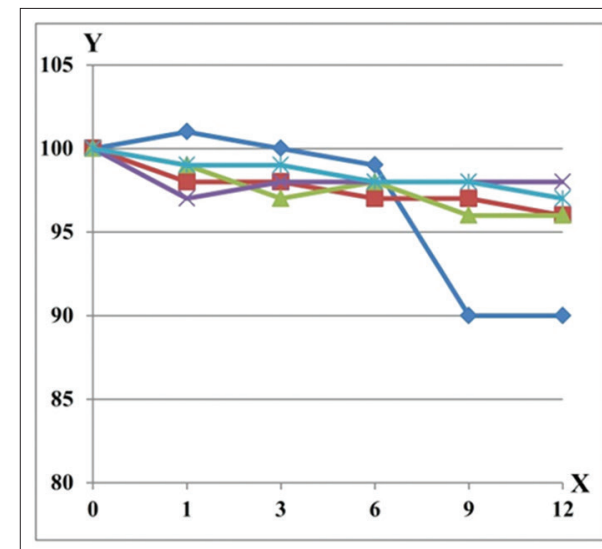

Total free organic acids

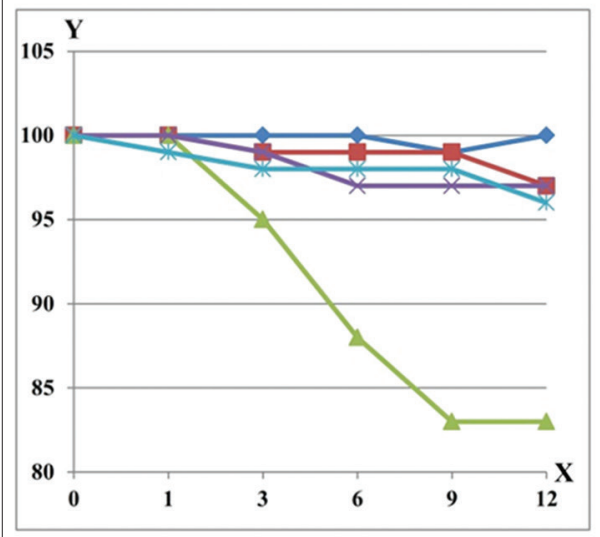

Total flavonoids

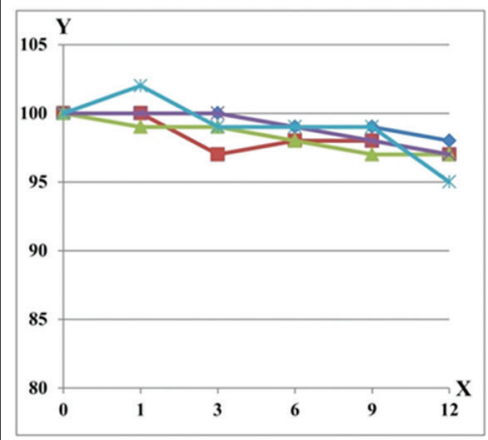

Total polysaccharides

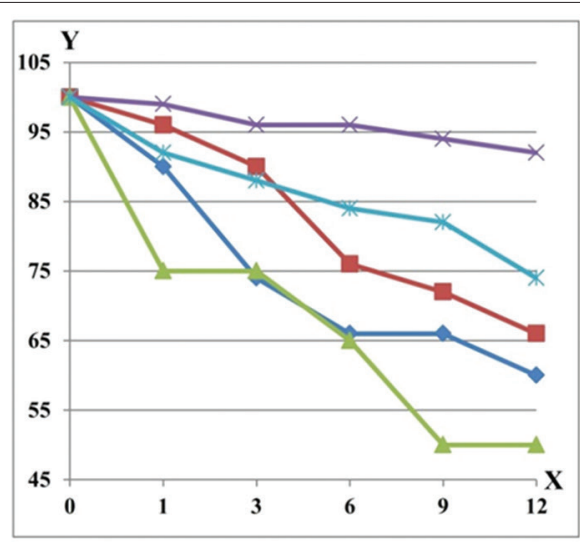

Ascorbic acid

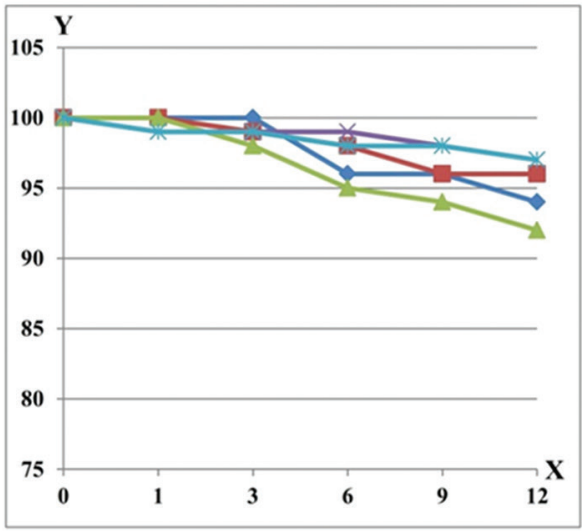

Total tannins

\section{$\neg \quad$ Hawthorn fruits \\ Raspberry fruits \\ Cinnamon rose fruits \\ Black chokeberry fruits}

Y-axis - part of BAS from the initial content, \% $\mathrm{X}$-axis - time, months

Fig. 4: Dynamics of biologically active substances content during the storage of dried Rosaceae fruits. The results of total anthocyanins determination are presented for raspberry and black chokeberry fruits as total flavonoid content

total anthocyanins were destroyed to a higher extent, their content did not exceed 40, 50, and 20\% (respectively) of the amount in fresh CHD. Oven drying reduced the content of total polysaccharides and total flavonoids by $15-20 \%$.

The study of BAS stability in frozen and dried Rosaceae fruits was conducted for 1 year. The initial data, as well as the intervals of $1,3,6$, 9, and 12 months, were taken as reference points (Figs. 3 and 4). Frozen fruits were stored in a freezer at $-18^{\circ} \mathrm{C}$, dried fruits - in paper bags at room temperature.

It has been established that during frozen fruits storage, the content of total flavonoids and total polysaccharides did not change after
12 months, and the content of total free organic acids even increased. The tendency to a constant decrease in the amount was observed in ascorbic acid and total tannins: In the first 6 months, an average of $15 \%$ and $12 \%$, respectively, during the period from 9 to 12 months, losses of ascorbic acid in the fruits were $28 \%$, total tannins - $24 \%$.

During the dried fruits storage (from 1 to 12 months), the content of total free organic acids, total polysaccharides, total flavonoids, and total tannins did not change significantly. A decrease from the initial content to $40-50 \%$ is typical for the ascorbic acid in dried fruits after 12 months of storage. Furthermore, the content of total anthocyanins in the dried raspberry fruits has been reduced by $17 \%$ by the end of the storage. 
Table 1: The content of biologically active substances in different types of Rosaceae fruits $(\mathrm{n}=5, \mathrm{f}=4, \mathrm{P}=95 \%, \mathrm{~T}(\mathrm{f}, \mathrm{P})=2.78)$

\begin{tabular}{|c|c|c|c|c|c|}
\hline \multirow[t]{2}{*}{ CHD } & \multicolumn{5}{|l|}{ BAS content, $\%$} \\
\hline & Total free organic acids & Ascorbic acid & Total flavonoids & Total tannins & Total polysaccharides \\
\hline \multicolumn{6}{|c|}{ Hawthorn fruits } \\
\hline Frozen & $2.57 \pm 0.03$ & $0.076 \pm 0.004$ & $0.16 \pm 0.02$ & $1.78 \pm 0.14$ & $5.07 \pm 0.08$ \\
\hline Dried & $0.90 \pm 0.02$ & $0.030 \pm 0.002$ & $0.15 \pm 0.01$ & $1.36 \pm 0.07$ & $4.53 \pm 0.05$ \\
\hline \multicolumn{6}{|c|}{ Cinnamon rose fruits } \\
\hline Fresh & $4.72 \pm 0.01$ & $1.31 \pm 0.03$ & $0.21 \pm 0.01$ & $7.12 \pm 0.11$ & $4.32 \pm 0.12$ \\
\hline Frozen & $4.67 \pm 0.06$ & $1.17 \pm 0.06$ & $0.20 \pm 0.01$ & $6.41 \pm 0.07$ & $4.22 \pm 0.06$ \\
\hline Dried & $2.15 \pm 0.04$ & $0.32 \pm 0.02$ & $0.18 \pm 0.01$ & $3.24 \pm 0.08$ & $4.17 \pm 0.08$ \\
\hline \multicolumn{6}{|c|}{ Mountain-ash fruits } \\
\hline Fresh & $5.90 \pm 0.03$ & $0.31 \pm 0.07$ & $0.24 \pm 0.01$ & $4.27 \pm 0.02$ & $4.43 \pm 0.07$ \\
\hline Frozen & $5.78 \pm 0.02$ & $0.28 \pm 0.07$ & $0.22 \pm 0.03$ & $3.66 \pm 0.04$ & $4.32 \pm 0.06$ \\
\hline Dried & $3.35 \pm 0.02$ & $0.12 \pm 0.03$ & $0.19 \pm 0.02$ & $2.35 \pm 0.07$ & $4.30 \pm 0.08$ \\
\hline \multicolumn{6}{|c|}{ Raspberry fruits* } \\
\hline Fresh & $7.40 \pm 0.02$ & $0.18 \pm 0.01$ & $0.90 \pm 0.01$ & $5.06 \pm 0.14$ & $6.33 \pm 0.13$ \\
\hline Frozen & $6.53 \pm 0.04$ & $0.17 \pm 0.01$ & $0.71 \pm 0.02$ & $4.03 \pm 0.09$ & $5.85 \pm 0.09$ \\
\hline \multicolumn{6}{|c|}{ Black chokeberry fruits* } \\
\hline Fresh & $5.19 \pm 0.04$ & $0.19 \pm 0.07$ & $5.99 \pm 0.07$ & $9.41 \pm 0.14$ & $5.22 \pm 0.08$ \\
\hline Frozen & $4.92 \pm 0.01$ & $0.17 \pm 0.08$ & $4.08 \pm 0.06$ & $8.50 \pm 0.09$ & $4.88 \pm 0.12$ \\
\hline Dried & $3.24 \pm 0.02$ & $0.08 \pm 0.02$ & $2.51 \pm 0.05$ & $4.43 \pm 0.07$ & $4.20 \pm 0.09$ \\
\hline
\end{tabular}

$\mathrm{n}$ : Number of repeat tests, f: Number of degrees of freedom, $\mathrm{p} \%$ : Confidence figure, $\mathrm{T}$ (f, P): Student's coefficient.

\section{CONCLUSION}

For the $1^{\text {st }}$ time, new data were obtained showing the effect of negative temperatures on the content of certain BAS groups (total free organic acids, total polysaccharides, total flavonoids, total anthocyanins, and total tannins) in five kinds of Rosaceae fruits (Siberian hawthorn, mountain-ash, black chokeberry, European raspberry, and cinnamon rose). Results show that freezing as a conservation method allows to preserve more BAS in the Rosaceae fruits. Frozen CHD can be proposed as an alternative to fresh and dried CPB for the preparation of allopathic and homeopathic medicines. CHD developed using oven drying was found to have the smallest BAS content compared to other conservation procedures that also confirm the research data $[18,20,26]$.

Dynamics of BAS content studies during the storage of frozen Rosaceae fruits indicates that shelf life should be 12 months in a freezer at the temperature no higher than $-18^{\circ} \mathrm{C}$ in polyethylene bags (Grade $\mathrm{H}$ - food grade).

\section{ACKNOWLEDGMENTS}

Supported by the "Russian Academic Excellence Project 5-100".

\section{AUTHORS' CONTRIBUTIONS}

Sergunova E.V. was engaged in scientific development and carrying out experiment. Bokov D.O. compiled literary review and wrote the draft of the manuscript.

\section{CONFLICTS OF INTEREST}

There are no conflicts of interest.

\section{REFERENCES}

1. State Register of Medicines Permitted for Medical Use. Moscow; 1998.

2. Russian State Pharmacopoeia. $11^{\text {th }}$ ed., Vol. 11. Moscow: Medicine; 1990.

3. Dasgupta S, Pandya M, Patel N. Antioxidant activities of some less utilized edible fruits. Int J Curr Pharm Res 2017;9:28-31.

4. Shafi S. Some uncommon fruits of the amazing world. Int J Pharm Pharm Sci 2014;6:54-8.

5. Bazamova YG, Ivanchenko OB. Investigation of the composition of biologically active substances in extracts of wild plants. Vopr Pitan 2016;85:100-7.

6. Brand MH, Connolly BA, Levine LH, Richards JT, Shine SM,
Spencer LE. Total anthocyanins, total phenolics, orac and moisture content of wild and cultivated dark-fruited Aronia species. Sci Hortic 2017;224:332-42.

7. Katalinic V, Milos M, Kulisic T, Jukic M. Screening of 70 medicinal plant extracts for antioxidant capacity and total phenols. Food Chem 2006;94:550-7.

8. Kurkina AV. Determination of total flavonoids in Siberian hawthorn fruit. Pharm Chem J 2015;12:800-3.

9. Teleszko M, Wojdyło A. Comparison of phenolic compounds and antioxidant potential between selected edible fruits and their leaves. J Funct Foods 2015;14:736-46.

10. Ahmed AA, Nath B. Formulation and in vitro evaluation of polyherbal anti-ageing face cream of Coriandrum sativum and rose hip oil. Int $\mathrm{J}$ Curr Pharm Res 2017;9:75-8.

11. Kausar R, Akhtar N. Evaluation of depegmenting and antierythemic effects of cosmetic emulgels containing raspberry fruit extract on human cheek skin. Int J Pharm Pharm Sci 2016;9:236-8.

12. European Medicines Agency. Reflection Paper on Microbiological Aspects of Herbal Medicinal Products and Traditional Herbal Medicinal Products 2015. Committee on Herbal Medicinal Products; 2015. Available from: http://www.ema.europa.eu/ema/pages/includes/ document/open_document.jsp?webContentId=WC500187592. [Last accessed on 2018 Mar 08].

13. Samylina IA, Kiseleva TL. Standardization of fresh raw medicinal plant material. Farmaciya 2007;1:49-51.

14. Sushma KS, Rajeshwari P, Raveesha KA. Comparative study of mycoflora, antibacterial activity and phytochemistry of selected fresh and stored medicinal fruits. Int J Pharm Pharm Sci 2017;9:43-8.

15. Shah S, Bhagwat A. Evaluation of phytochemicals, antioxidant capacity and antibacterial action of the fruit of Thespesia populnea (L.) Sol. ex. Correa. Int J Pharm Pharm Sci 2015;7:117-21.

16. Frolov SV, Danin VV, Kremnevskaya MI. Losses during freezing and refrigerating storage of fruits. Bull Int Acad Refrigeration 2008;1:35-8.

17. Shishkina NS, Lezhneva ML, Karastoyanova OV, Feskov OA. Cryogenic freezing of berries, fruits and vegetables. Manufacture Sale Frozen Fast Frozen Foods 2004;6:34-7.

18. Rocha RP, Melo EC. Influence of drying process on the quality of medicinal plants: A review. J Med Plant Res 2011;5:7076-84.

19. Thi ND, Hwang ES. Effects of drying methods on contents of bioactive compounds and antioxidant activities of black chokeberries (Aronia melanocarpa). Food Sci Biotechnol 2016;1:55-61.

20. Abascal K, Ganora L, Yarnell E. The effect of freeze-drying and its implications for botanical medicine: A review. Phytother Res 2005; 19:655-60.

21. Abdullina SG, Agapova NM, Lira OA, Khaziev RS, Kodryanu NP. Coulometric determination of the free organic acid content in wild-rose fruit. Pharm Chem J 2011;5:282-4.

22. Andreeva VY, Kalinkina GI, Kolomiets NE, Isaikina NV. Procedure 
for determination of antocyans in the black chokeberries (Aronia melanocarpa). Farmaciya 2013;3:19-21.

23. Checheta OV, Safonova EF, Slivkin AI. Research of flavonoides composition of fruits of a plant of sort Rosa by method TLC. Bulletin of the Voronezh State University. Ser Chem Biol Farmaciya 2011;1:205-9. 24. European Pharmacopoeia Commission. European Pharmacopoeia. $6^{\text {th }}$ ed. Strasbourg: European Pharmacopoeia Commission; 2008.

25. Russian State Pharmacopoeia. $11^{\text {th }}$ ed., Vol. 11. Moscow: Medicine; 1987.

26. Mahanom H Jr., Azizah A, Dzulkifly M. Effect of different drying methods on concentrations of several phytochemicals in herbal preparation of 8 medicinal plants leaves. Malays J Nutr 1999;5:47-54 